\title{
Penyelesaian Persamaan Telegraph Dan Simulasinya
}

\author{
Agus Miftakus Surur ${ }^{1}$, Yudi Ari Adi $^{2}$, dan Sugiyanto ${ }^{3}$ \\ 1,3Program Studi Matematika Fakultas Sains dan Teknologi, UIN Sunan Kalijaga, Jl. Marsda \\ Adisucipto No. 1 Yogyakarta, Indonesia \\ ${ }^{2}$ Program Studi Matematika, Fakultas MIPA, Universitas Ahmad Dahlan, Jl. Prof. Dr. Soepomo, SH \\ Janturan Yogyakarta, Indonesia
}

Korespondensi; Sugiyanto, Email: sugimath@yahoo.com

\begin{abstract}
Abstrak
Persamaan Telegraph adalah salah satu jenis dari persamaan gelombang. Pemecahan persamaan gelombang dapat diperoleh dengan menggunakan fungsi Green dengan metode kondisi batas. Penelitian ini bertujuan untuk menunjukkan proses mendapatkan rumus matematika dari persamaan gelombang dan juga mengetahui bentuk solusi persamaan gelombang dengan menggunakan fungsi Green. Hasil analisis menunjukkan bahwa proses mendapatkan rumus matematis dari persamaan gelombang dari fungsi Green yang berlaku dalam persamaan yang berhubungan dengan persamaan gelombang, yang diterapkan pada persamaan Telegraph. Solusi dimulai dengan mencari bentuk publik dari fungsi Green, selanjutnya mencari penyelesaian persamaan gelombang dalam fungsi Green. Aplikasi dari persamaan gelombang digunakan untuk mencari penyelesaian persamaan Telegraph. Hasil dari persamaan Telegraph yang telah diperoleh akan ditampilkan dalam bentuk gambar (Bisa diketahui dengan simulasi) sehingga bentuk dari persamaan Telegraph.
\end{abstract}

Kata Kunci: Fungsi Green; Persamaan gelombang; Persamaan Telegraph

\begin{abstract}
Equation Telegraph is one of type from wave equation. Solving of the wave equation obtainable by using Green's function with the method of boundary condition problem. This research aim to to show the process obtain;get the mathematical formula from wave equation and also know the form of solution of wave equation by using Green's function. Result of analysis indicate that the process get the mathematical formula from wave equation from applicable Green's function in equation which deal with the wave equation, that is applied in equation Telegraph. Solution started with searching public form from Green's function, hereinafter look for the solving of wave equation in Green's function. Application from the wave equation used to look for the solving of equation Telegraph. Result from equation Telegraph which have been obtained will be shown in the form of picture (knowable to simulasi) so that form of the the equation Telegraph.
\end{abstract}

Keywords: Green's function; Wave equation; Equation Telegraph

\section{Pendahuluan}

Fungsi Green merupakan suatu fungsi yang mempunyai kriteria khusus. Fungsi Green juga dapat digunakan untuk menyelesaikan persamaan diferensial parsial: persamaan Gelombang dan persamaan Panas. Cabang dari persamaan Gelombang ada beberapa persamaan diantaranya persamaan Schrodinger dan persamaan Telegraph.

Persamaan Telegraph adalah persamaan yang diambil sebagai aplikasi dari persamaan Gelombang yang diselesaikan dengan fungsi Green dengan metode masalah syarat batas dari persamaan diferensial.

\section{Persamaan Telegraph}

Suatu aliran listrik pada sebuah kabel dapat diuraikan dengan menggunakan persamaan diferensial parsial 


$$
u_{x x}=C L u_{t t}+(R C+C L) u_{T}+R G u
$$

Persamaan diferensial parsial di atas disebut dengan Persamaan Telegraph. Dimana $R$ adalah suatu daya, $L$ adalah suatu induksi, $C$ adalah suatu kapasitor, dan $G$ adalah suatu kebocoran, dari semua bagian tersebut diukur panjangnya (besarnya) dari suatu kabel. Suatu fungsi yang tidak diketahuin $u(x ; t)$ bisa menggambarkan besarnya tegangan volt atau arus pada suatu waktu $t$, pada posisi $x$ dari suatu kabel tersebut dimana $t>0,-\infty<x<\infty$.

Untuk memperoleh bentuk yang lebih sesuai dalam menguraikan ini, maka dengan memberikan permisalan

$$
2 \beta=\frac{R}{L}+\frac{G}{C}, c^{2}=\frac{1}{C L}, \alpha=\frac{R G}{C L}
$$

Sehingga menghasilkan persamaan

$$
u_{t t}+2 \beta u_{t}+\alpha u=c^{2} u_{x x}
$$

Dari persamaan menggambarkan

$$
\beta^{2}-\alpha=\frac{1}{4}\left(\frac{R}{L}-\frac{G}{C}\right)^{2}
$$

Dengan demikian hanya membutuhkan penyelesaian dari persamaan (1) dari nilai $\alpha$ dan $\beta$ dengan ketentuan $\beta^{2}-\alpha \geq 0$. (1) diselesaikan dari nilai yang berubah-ubah pada $\alpha, \beta$. Untuk lebih detailnya, dipunyai dua kasus:

Kasus I $: \beta^{2}>\alpha$

Kasus II $: \beta^{2}=\alpha$

Karena persamaan Telegraph merupakan orde dua, maka untuk dasar menetapkan dua kondisi awal:

$$
u(x ; 0)=f_{1}(x), u_{t}(x ; 0)=f_{2}(x)
$$

Persamaan tersebut adalah linear dan homogen, maka pertama dapat menyelesaikannya dengan $f_{1}=0$, kemudian menyelesaikan dengan $f_{2}=0$, dan menjumlahkan hasil-hasilnya.

Sebagai pendahuluan penyederhanaan, didefinisikan $u(x ; t)=u(x ; t) e^{\beta t}$ transformasi dari persamaan telegraph untuk bentuk khusus dengan $\beta=0$, supaya persamaan menjadi $u_{t t}=c^{2} v_{x x}+$ $k^{2} v$, yang sesuai untuk kasus 1 .

1. Kasus I

Pada kasus 1 yaitu $\alpha<\beta^{2}$, yang merupakan masalah nilai awal dari $v_{t t}-c^{2} v_{x x}=k^{2} v$ dengan $v(x ; 0)=f_{1}(x), v_{t}(x ; 0)=f_{2}(x)$.

Untuk menghubungkan susunan tersebut pada persamaan gelombang, dimasukkan sebuah variabel baru yang bebas yaitu $y$ dan fungsi menjadi

$$
w(x ; y ; t)=v(x ; t) e^{\left(\frac{k y}{c}\right)}
$$

Untuk fungsi ini, dipunyai $w_{t t}=v_{t t} e^{\left(\frac{k y}{c}\right)}, w_{x x}=v_{x x} e^{\left(\frac{k y}{c}\right)}, w_{y y}=(k / c)^{2} v e^{\left(\frac{k y}{c}\right)}$, sehingga persamaan menjadi

$$
w_{t t}-c^{2}\left(w_{t t}+w_{y y}\right)=0
$$


Dengan $w(x ; y ; 0)=f_{1}(x) e^{\left(\frac{k y}{c}\right)}, w(x ; y ; 0)=f_{2}(x) e^{\left(\frac{k y}{c}\right)}$.

Persamaan gelombang ini diselesaikan dengan formula

$$
w(x ; y ; t)=\frac{d}{d t}\left(t M_{c t} F_{1}\right)+t M_{c t} F_{2}
$$

Dimana $F_{1}(x, y)=f_{1} e^{\left(\frac{k y}{c}\right)}, F_{2}(x, y)=f_{2} e^{\left(\frac{k y}{c}\right)}$.

Nilai operator rata-ratanya adalah dinyatakan dari:

$$
\begin{aligned}
M_{c t} F_{1}(x, y) & =\frac{1}{2 \pi c t} \iint_{|\xi|<c t} \frac{F_{i}\left(x+\xi_{1}, y+\xi_{2}\right) d \xi_{1} d \xi_{2}}{\sqrt{(c t)^{2}-\xi_{1}^{2}-\xi_{2}^{2}}}, i=1,2 \\
& =\frac{1}{2 \pi c t} \iint_{|\xi|<c t} \frac{F_{i}\left(x+\xi_{1}\right) e^{\left(\frac{k}{c}\right)\left(y+\xi_{2}\right)}}{\sqrt{(c t)^{2}-\xi_{1}^{2}-\xi_{2}^{2}}} d \xi_{1} d \xi_{2}
\end{aligned}
$$

Untuk memperkirakan integral $\xi_{2}$, didefinisikan variabel baru dari pengintegralan dengan formula $\xi_{2}=\sqrt{(c t)^{2}-\xi_{1}^{2}} \cos \theta, 0<\theta<\pi$, untuk mendapatkan

$$
\int_{|\xi|<\sqrt{(c t)^{2}-\xi_{1}^{2}}} \frac{e^{\left(\frac{k}{c}\right)\left(y+\xi_{2}\right)}}{\sqrt{(c t)^{2}-\xi_{1}^{2}-\xi_{2}^{2}}} d \xi_{2}=e^{\left(\frac{k y}{c}\right)} \int_{0}^{\pi} e^{\left(\frac{k}{c}\right)} \sqrt{(c t)^{2}-\xi_{1}^{2}} \cos \theta d \theta
$$

Pembuktian:

$$
\begin{gathered}
\xi_{2}=\sqrt{(c t)^{2}-\xi_{1}^{2}} \cos \theta d \xi_{2}=\sqrt{(c t)^{2}-\xi_{1}^{2}} \sin \theta d \theta \\
\begin{aligned}
\left(\xi_{2}\right)^{2} & =\left(\sqrt{(c t)^{2}-\xi_{1}^{2}} \cos \theta\right)^{2} \\
& =\left(\left((c t)^{2}-\xi_{1}^{2}\right) \cos ^{2} \theta\right) \\
& =\left(\cos ^{2} \theta(c t)^{2}-\cos ^{2} \theta \xi_{1}^{2}\right)
\end{aligned} \\
=\sqrt{\sqrt{(c t)^{2}-\xi_{1}^{2}-\xi_{2}^{2}}}=\sqrt{(c t)^{2}-\xi_{1}^{2}-\left(\cos ^{2} \theta(c t)^{2}-\cos ^{2} \theta \xi_{1}^{2}\right)} \\
=\sin ^{2} \theta \sqrt{(c t)^{2}-\xi_{1}^{2}} \\
\frac{e^{\left(\frac{k}{c}\right)\left(y+\xi_{2}\right)}}{\sqrt{(c t)^{2}-\xi_{1}^{2}-\xi_{2}^{2}}} d \xi_{2}=\int_{\left|\xi_{2}\right|<\sqrt{(c t)^{2}-\xi_{1}^{2}}} \frac{e^{\left(\frac{k y+k \xi_{2}}{c}\right)}}{\sqrt{(c t)^{2}-\xi_{1}^{2}-\xi_{2}^{2}}} d \xi_{2} \\
\int_{\left|\xi_{2}\right|<\sqrt{(c t)^{2}-\xi_{1}^{2}}}
\end{gathered}
$$




$$
\begin{aligned}
& =e^{\left(\frac{k y}{c}\right)} \int_{\left|\xi_{2}\right|<\sqrt{(c t)^{2}-\xi_{1}^{2}} \frac{e^{\left(\frac{k \xi_{2}}{c}\right)}}{\sqrt{(c t)^{2}-\xi_{1}^{2}-\xi_{2}^{2}}} d \xi_{2}} \int^{\left(\frac{k y}{c}\right)} \frac{e^{\left(\frac{k \sqrt{(c t)^{2}-\xi_{1}^{2}} \cos \theta}{c}\right)}}{\sin \theta \sqrt{(c t)^{2}-\xi_{1}^{2}}}\left(-\sqrt{(c t)^{2}-\xi_{1}^{2}} \sin \theta\right) d \theta \\
& =e^{\left(\frac{k y}{c}\right)} \int_{|\cos \theta| \leq 1}\left(\frac{e^{\left(\frac{k \sqrt{(c t)^{2}-\xi_{1}^{2}} \cos \theta \mid<\sqrt{(c t)^{2}-\xi_{1}^{2}}}{c} \cos \theta\right.}}{\sin \theta \sqrt{(c t)^{2}-\xi_{1}^{2}}}\right) d \theta \\
& =e^{\left(\frac{k y}{c}\right)} \int_{0}^{\pi} e^{\left(\frac{k}{c}\right)} \sqrt{(c t)^{2}-\xi_{1}^{2}} \cos \theta d \theta
\end{aligned}
$$

Hasil dari integral (3) telah diketahui pada fungsi Bessel, $I_{0}\left(\frac{k}{c}\right)\left(\sqrt{(c t)^{2}-\xi_{1}^{2}}\right)$. Menurut fungsi Bessel:

$$
\begin{aligned}
J_{0}(x) & =\frac{1}{2 \pi} \int_{-\pi}^{\pi} \cos (x \cos \theta) d \theta \\
I_{0}\left(\left(\frac{k}{c}\right) \sqrt{(c t)^{2}-\xi_{1}^{2}}\right) & =\frac{1}{2 \pi} \int_{-\pi}^{\pi} e\left(\frac{k}{c}\right) \sqrt{(c t)^{2}-\xi_{1}^{2}} \cos \theta d \theta \\
& =\frac{1}{2 \pi} \int_{-\pi}^{\pi} \cos \left(\left(\frac{k}{c}\right) \sqrt{(c t)^{2}-\xi_{1}^{2}} \cos \theta\right) d \theta \\
I_{0}\left(\left(\frac{k}{c}\right) \sqrt{(c t)^{2}-\xi_{1}^{2}}\right) & =\frac{1}{\pi}\left[\int_{0}^{\pi} \cos \left(\left(\frac{k}{c}\right) \sqrt{(c t)^{2}-\xi_{1}^{2}} \cos \theta\right) d \theta\right] \\
\pi I_{0}\left(\left(\frac{k}{c}\right) \sqrt{(c t)^{2}-\xi_{1}^{2}}\right) & =\frac{1}{\pi} \int_{0}^{\pi} \cos \left(\left(\frac{k}{c}\right) \sqrt{(c t)^{2}-\xi_{1}^{2}} \cos \theta\right) d \theta
\end{aligned}
$$

Dengan demikian diperoleh

$$
M_{c t} F_{1}(x, y)=\frac{1}{2 \pi c t} \iint_{|\xi|<c t} \frac{f_{i}\left(x+\xi_{1}\right) e^{\left(\frac{k}{c}\right)\left(y+\xi_{2}\right)}}{\sqrt{(c t)^{2}-\xi_{1}^{2}-\xi_{2}^{2}}} d \xi_{1} d \xi_{2}
$$




$$
\begin{aligned}
& =\frac{1}{2 \pi c t} \int_{-c t}^{c t} f_{i}\left(x+\xi_{1}\right) d \xi_{1} \int_{|\xi|<\sqrt{(c t)^{2}-\xi_{1}^{2}}} \frac{e^{\left(\frac{k}{c}\right)\left(y+\xi_{2}\right)}}{\sqrt{(c t)^{2}-\xi_{1}^{2}-\xi_{2}^{2}}} d \xi_{2} \\
& =\frac{1}{2 \pi c t} \int_{-c t}^{c t} f_{i}\left(x+\xi_{1}\right) d \xi_{1} e^{\left(\frac{k}{c}\right)} \int_{0}^{\pi} e^{\left(\frac{k}{c}\right)} \sqrt{(c t)^{2}-\xi_{1}^{2}} \cos \theta d \theta \\
& =e^{\left(\frac{k}{c}\right)} \frac{1}{2 \pi c t} \int_{-c t}^{c t} f_{i}\left(x+\xi_{1}\right) d \xi_{1} \pi I_{0}\left(\left(\frac{k}{c}\right) \sqrt{(c t)^{2}-\xi_{1}^{2}}\right) \\
& =e^{\left(\frac{k}{c}\right)} \frac{1}{2 c t} \int_{-c t}^{c t} f_{i}\left(x+\xi_{1}\right) I_{0}\left(\frac{k}{c} \sqrt{(c t)^{2}-\xi_{1}^{2}}\right) d \xi_{1}
\end{aligned}
$$

Dengan demikian factor $e^{\left(\frac{k y}{c}\right)}$, didapatkan penyelesaian persamaan Telegraph dengan $f_{1}=0$. Untuk menemukan penyelesaian yang lebih umum, dibutuhkan mendiferensialkan integral tersebut terhadap $t$ :

$$
\begin{gathered}
\frac{d}{d t}\left(t M_{c t} f_{i}\right) \\
=\frac{1}{2 c}\left[f_{i}(x+c t)+f_{i}(x-c t)\right]+\frac{1}{2 c t} \int_{-c t}^{c t} f_{i}\left(x+\xi_{1}\right) \frac{d}{d t}\left\{I_{0}\left[\frac{k}{c} \sqrt{(c t)^{2}-\xi_{1}^{2}}\right]\right\} d \xi_{1}
\end{gathered}
$$

Akan tetapi turunan dari fungsi Bessel $I_{0}$ adalah fungsi Bessel $I_{1}: I_{0}^{\prime}=I_{1}$. Dengan demikian disimpulkan bahwa

$$
\frac{d}{d t}\left(t M_{c t} f_{i}\right)=\frac{1}{2 c}\left[f_{i}(x+c t)+f_{i}(x-c t)\right]+\frac{k}{2} \int_{-c t}^{c t} f_{i}\left(x+\xi_{1}\right) I_{1}\left[\frac{k}{c} \sqrt{(c t)^{2}-\xi_{1}^{2}}\right] d \xi
$$

Gambaran secara jelas dari penyelesaian persamaan Telegraph $v_{t t}-c^{2} v_{x x}=k^{2} v$ dengan $v(x ; 0)=f_{1}(x), v_{t}(x ; 0)=f_{2}(x)$ seperti yang ditunjukkan oleh

$$
\begin{aligned}
v(x ; t)= & \frac{1}{2 c} \int_{-c t}^{c t} f_{2}(x+\xi) I_{0}\left[\frac{k}{c} \sqrt{(c t)^{2}-\xi^{2}}\right] d \xi \\
& +\frac{1}{2 c}\left[f_{1}(x+c t)+f_{1}(x-c t)\right]+\frac{k 1}{2} \int_{-c t}^{c t} f_{2}(x+\xi) I_{1}\left[\frac{k}{c} \sqrt{(c t)^{2}-\xi^{2}}\right] d \xi
\end{aligned}
$$

2. Kasus II

Pada kasus 2 yaitu $\alpha=\beta^{2}$, yang merupakan masalah nilai awal dari

$$
v_{t t}-c^{2} v_{x x}=0
$$

dengan $v(x ; 0)=f_{1}(x), v_{t}(x ; 0)=f_{2}(x)$.

Untuk menyelesaikan (7) digunakan Transformasi Fourier 


$$
F_{k}(\mu)=\frac{1}{2 \pi} \int_{-\infty}^{\infty} e^{-i \mu x} f_{i}(x) d x \quad k=1,2
$$

Dengan membalikkan formula, sehingga diperoleh

$$
f_{k}(x)=\int_{-\infty}^{\infty} e^{i \mu x} F_{i}(\mu) d \mu \quad k=1,2
$$

Gambaran Fourier yang diinginkan dari penyelesaian $v$ adalah

$$
v(x ; t)=\int_{-\infty}^{\infty} V(\mu, t) e^{i \mu x} d \mu
$$

Dimana $V(\mu, t)$ adalah fungsi yang akan ditentukan. Untuk melakukan ini, (10) disubsitusikan ke dalam persamaan gelombang $(7)$

$$
0=\left[\int_{-\infty}^{\infty} V(\mu ; t)+c^{2} \mu^{2} V(\mu ; t)\right] e^{i \mu x} d \mu
$$

Ini diperlukan oleh untuk menyelesaikan persamaan diferensial biasa

$$
V_{t t}+c^{2} \mu^{2} V(\mu ; t)=0
$$

Sehingga

$$
V(\mu ; t)=A(\mu) \cos \mu c t+B(\mu) \sin \mu c t
$$

Untuk memperoleh $A(\mu)$ dan $B(\mu)$, diberikan $t=0$ pada (10) dan (11)

$$
v(x ; 0)=\int_{-\infty}^{\infty} A(\mu) e^{i \mu x} d \mu, v_{t}(x ; 0)=\int_{-\infty}^{\infty} \mu c B(\mu) e^{i \mu x} d \mu
$$

Membandingkan dengan (9) dan kondisi awal dari (7), dipunyai

$$
F_{1}(\mu)=A(\mu), F_{2}(\mu)=\mu c B(\mu)
$$

Disubtitusikan ke dalam (11) dan mengembalikan dari (10). Diperoleh gambaran Fourier

$$
v(x ; t)=\int_{-\infty}^{\infty}\left[F_{1}(\mu) \cos \mu c t+F_{2}(\mu) \frac{\sin \mu c t}{\mu c}\right] e^{i \mu x} d \mu
$$

Dengan menggunakan (12) didapatkan gambaran yang berhubungannya dengan fungsi-fungsi $f_{1}(x), f_{2}(x)$ yang telah diberikan. Ingat kembali bahwa

$$
\cos \theta=\frac{1}{2}\left(e^{i \theta}+e^{-i \theta}\right) \sin \theta=\frac{1}{2 i}\left(e^{i \theta}-e^{-i \theta}\right)
$$

Maka

$$
\begin{aligned}
\int_{-\infty}^{\infty} F_{1}(\mu) \cos \mu c t e^{i \mu x} d u & =\int_{-\infty}^{\infty} F_{1}(\mu) \frac{1}{2}\left(e^{i \mu c t}+e^{-i \mu c t}\right) e^{i \mu x} d \mu \\
& =\frac{1}{2} \int_{-\infty}^{\infty} F_{1}(\mu)\left(e^{i \mu(x+c t)}+e^{-i \mu(x-c t)}\right) d \mu
\end{aligned}
$$




$$
=\frac{1}{2}\left[f_{1}(x+c t)+f_{1}(x-c t)\right]
$$

Dengan cara yang sama

$$
\begin{aligned}
\int_{-\infty}^{\infty} F_{2}(\mu) \frac{\sin \mu c t}{\mu c} e^{i \mu x} d \mu & =\int_{-\infty}^{\infty} F_{2}(\mu) \frac{1}{2}\left(\frac{e^{i \mu c t}-e^{-i \mu c t}}{i \mu c}\right) e^{i \mu x} d \mu \\
& =\frac{1}{2} \int_{-\infty}^{\infty} F_{2}(\mu)\left(\frac{e^{i \mu(x+c t)}-e^{i \mu(x-c t)}}{i \mu c}\right) d \mu \\
& =\frac{1}{2 c} \int_{-\infty}^{\infty} F_{2}(\mu)\left(\int_{x-c t}^{x+c t} e^{i \mu \xi}\right) d \mu \\
& =\frac{1}{2 c} \int_{x-c t}^{x+c t}\left(\int_{-\infty}^{\infty} e^{i \mu \xi} F_{2}(\mu) d \mu\right) d \xi \\
& =\frac{1}{2 c} \int_{x-c t}^{x+c t} f_{2}(\xi) d \xi
\end{aligned}
$$

Dari hasil di atas jika keduanya dijumlahkan maka akan diperoleh:

$$
v(x ; t)=\frac{1}{2}\left[f_{1}(x+c t)+f_{1}(x-c t)\right]+\frac{1}{2 c} \int_{x-c t}^{x+c t} f_{2}(\xi) d \xi
$$

Inilah bentuk persamaan Telegraph pada saat kasus II.

\section{Simulasi Persamaan Telegraph}

Simulasi, pada penelitian ini adalah bentuk (gambar) dari persamaan telegraph setelah di-plot ke dalam salah satu software ternama yaitu Mathematica versi 6, sehingga diketahui bentuk dari persamaan Telegraph berdasar dari persamaan yang telah didapatkan di atas.

Sebagai langkah awal untuk mencari simulasi persamaan Telegraph ini, dimasukkan suatu nilai (angka) pada variabel.

$$
\begin{aligned}
v(x ; t)= & \frac{1}{2 c} \int_{-c t}^{c t} f_{2}(x+\xi) I_{0}\left[\frac{k}{c} \sqrt{(c t)^{2}-\xi^{2}}\right] d \xi \\
& +\frac{1}{2 c}\left[f_{1}(x+c t)+f_{1}(x-c t)\right]+\frac{k 1}{2} \int_{-c t}^{c t} f_{2}(x+\xi) I_{1}\left[\frac{k}{c} \sqrt{(c t)^{2}-\xi^{2}}\right] d \xi
\end{aligned}
$$

Dengan nilai tiap-tiap variabelnya: $k=1 ; c=1 ; \xi=1 ;$ interval $x=\{x \mid 3 \leq x \leq 4\} ; t=$ $\{x \mid 1 \leq t \leq 2\}$ dan $f_{1}=x, f_{2}=x^{2}$, berikut adalah output pada kasus I: 


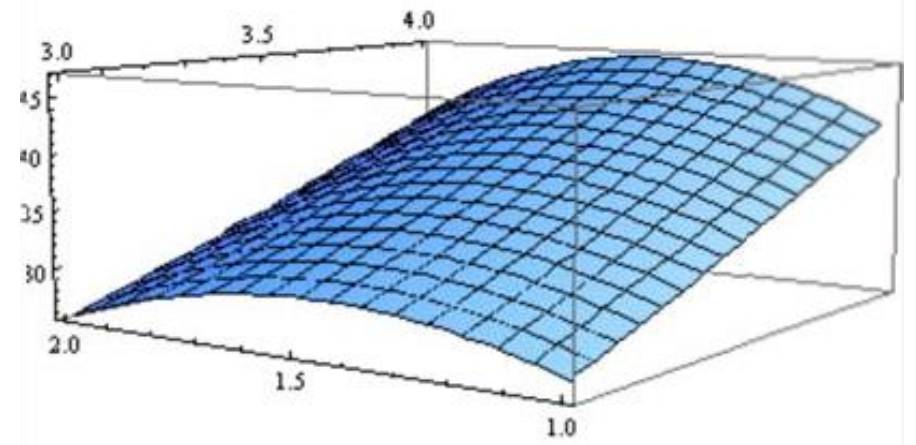

Gambar 1 Output pada interval $x=\{x \mid 3 \leq x \leq 4\} ; t=\{t \mid 1 \leq t \leq 2\}$.

Pada interval $x=\{x \mid 1 \leq x \leq 5\} ; t=\{t \mid 1 \leq t \leq 20\}$, simulasinya:

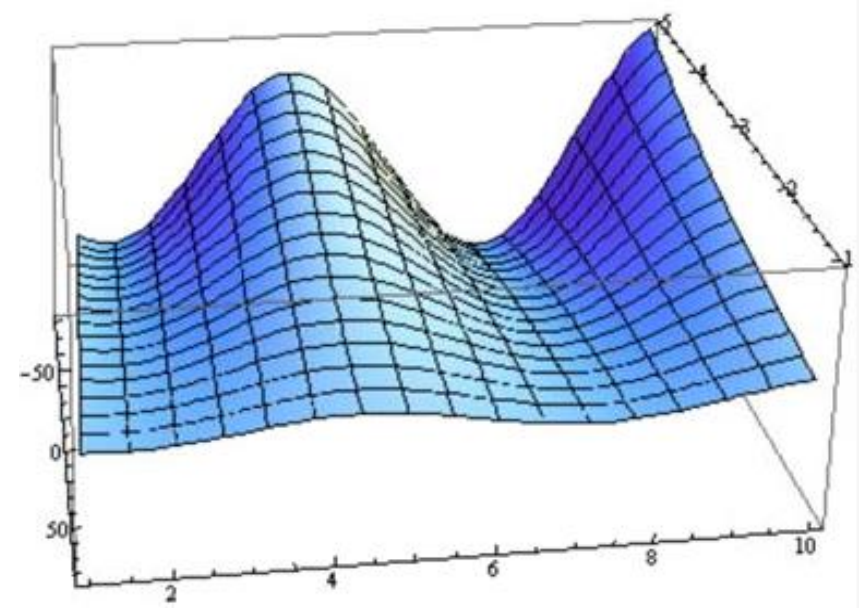

Gambar 2 Output pada interval $x=\{x \mid 1 \leq x \leq 5\} ; t=\{t \mid 1 \leq t \leq 20\}$.

Pada interval $x=\{x \mid 0 \leq x \leq 10\} ; t=\{t \mid 0 \leq t \leq 20\}$

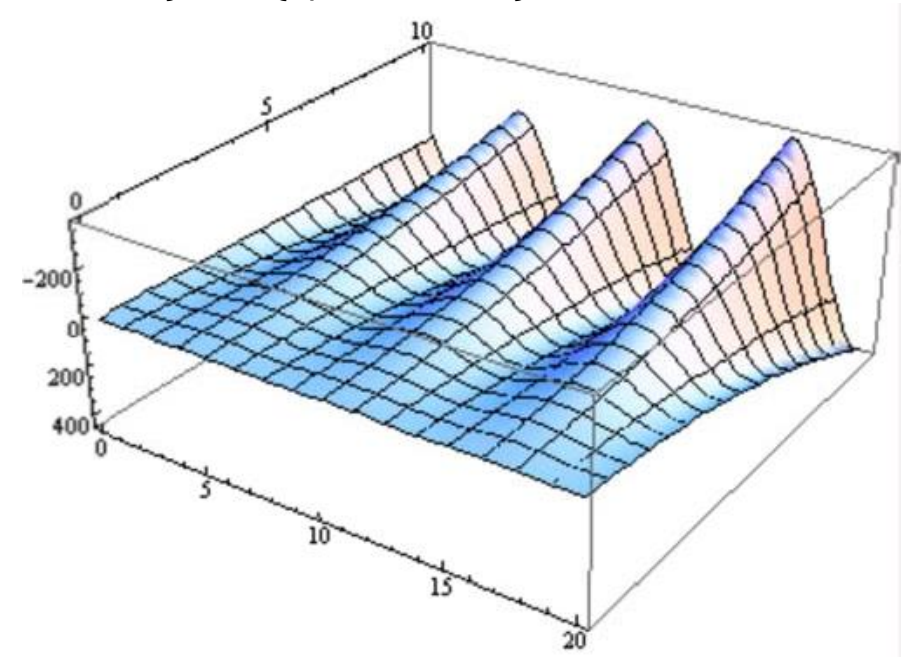

Gambar 3 Output pada interval $x=\{x \mid 0 \leq x \leq 10\} ; t=\{t \mid 0 \leq t \leq 20\}$.

Dari simulasi gambar 1, gambar 2, dan gambar 3, dapat diambil kesimpulan bahwa semakin besar nilai $t$ yang diberikan pada persamaan maa gelombang yang terbentuk semakin banyak, sehingga bentuk dari gelombang itu sendiri akan semakin tampak jelas. 
Selanjutnya aka dicari simulasi pada kasus II. Langkah untuk mencari simulasi hampir sama seperti langkah pada kasus I, hanya saja persamaan yang digunakan berbeda, sehingga hasil yang diperoleh juga berbeda dengan kasus $I$.

Diawali dengan mengambl persamaan yang sudah diperoleh dari penjabaran:

$$
v(x ; t)=\frac{1}{2}\left[f_{1}(x+c t)+f_{1}(x-c t)\right]+\frac{1}{2 c} \int_{x-c t}^{x+c t} f_{2}(\xi) d \xi
$$

Dengan nilai tiap variabelnya: $c=1$; interval $x=\{x \mid 1 \leq x \leq 2\} ; t=\{x \mid 2 \leq t \leq 20\}$ dan $f_{1}=$ $x, f_{2}=x^{2}$

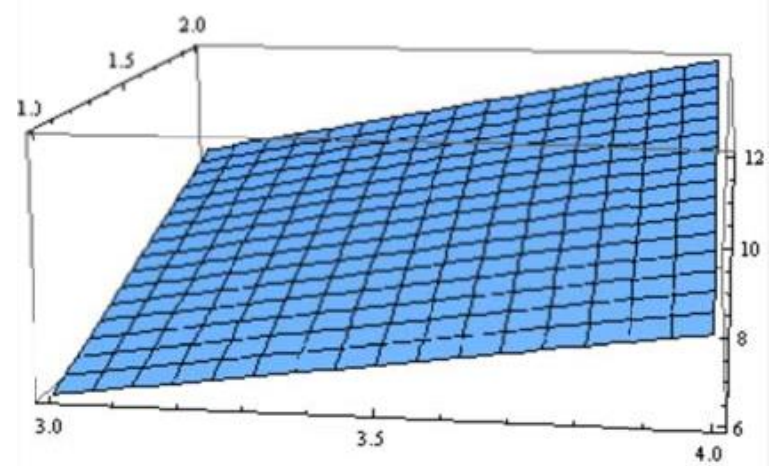

Gambar 4 Output pada interval $x=\{x \mid 1 \leq x \leq 2\}$.

Pada interval $x=\{x \mid 1 \leq x \leq 5\} ; t=\{t \mid 1 \leq t \leq 20\}$

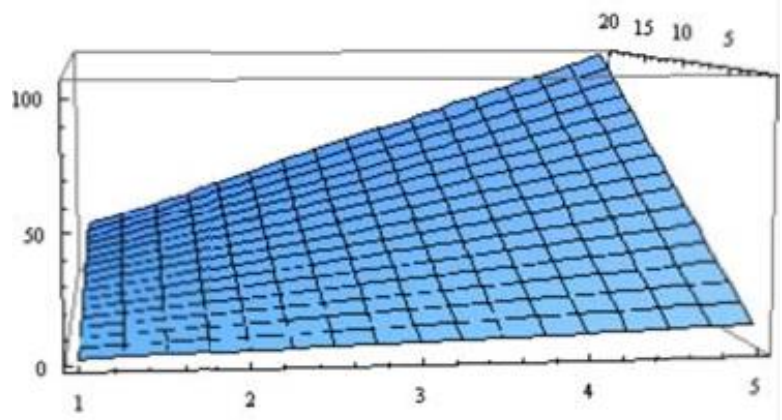

Gambar 5 Output pada interval $x=\{x \mid 1 \leq x \leq 5\} ; t=\{t \mid 1 \leq t \leq 20\}$.

Pada interval $x=\{x \mid 0 \leq x \leq 10\} ; t=\{t \mid 0 \leq t \leq 20\}$

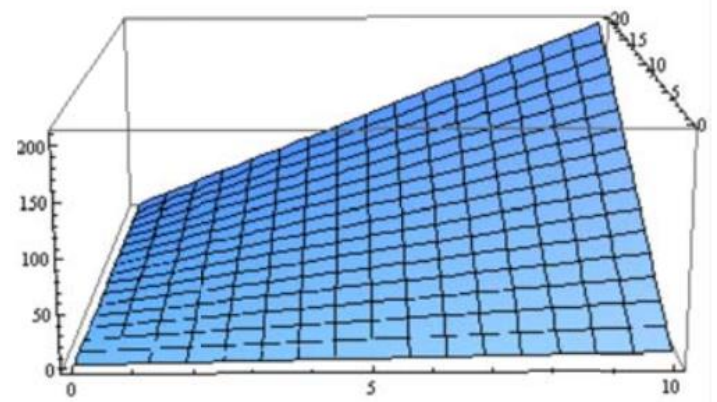

Gambar 6 Output pada interval $x=\{x \mid 0 \leq x \leq 10\} ; t=\{t \mid 0 \leq t \leq 20\}$.

Dari simulasi (gambar 4, gambar 5, dan gambar 6) dapat diambil kesimpulan bahwa nilai $x$ dan $t$ yang diberikan pada persamaan tidak terlalu mempengaruhi bentuk simulai. 


\section{Kesimpulan}

1. Persamaan Telegraph mempunyi bentuk umum

Dan mempunyai dua:

$$
u_{t t}+2 \beta u_{t}+\alpha u=c^{2} u_{x x}
$$

Kasus I: $\beta^{2}>\alpha$

Kasus II $: \beta^{2}=\alpha$

2. Kasus I memperoleh persamaan Telegraph

$$
\begin{aligned}
v(x ; t)= & \frac{1}{2 c} \int_{-c t}^{c t} f_{2}(x+\xi) I_{0}\left[\frac{k}{c} \sqrt{(c t)^{2}-\xi^{2}}\right] d \xi \\
& +\frac{1}{2 c}\left[f_{1}(x+c t)+f_{1}(x-c t)\right]+\frac{k 1}{2} \int_{-c t}^{c t} f_{2}(x+\xi) I_{1}\left[\frac{k}{c} \sqrt{(c t)^{2}-\xi^{2}}\right] d \xi
\end{aligned}
$$

Dan simulasinya dengan nilai tiap-tiap variabelnya:

$k=1 ; c=1 ; \xi=1 ;$ interval $x=\{x \mid 1 \leq x \leq 2\} ; t=\{x \mid 2 \leq t \leq 20\}$ dan $f_{1}=x, f_{2}=x^{2}$

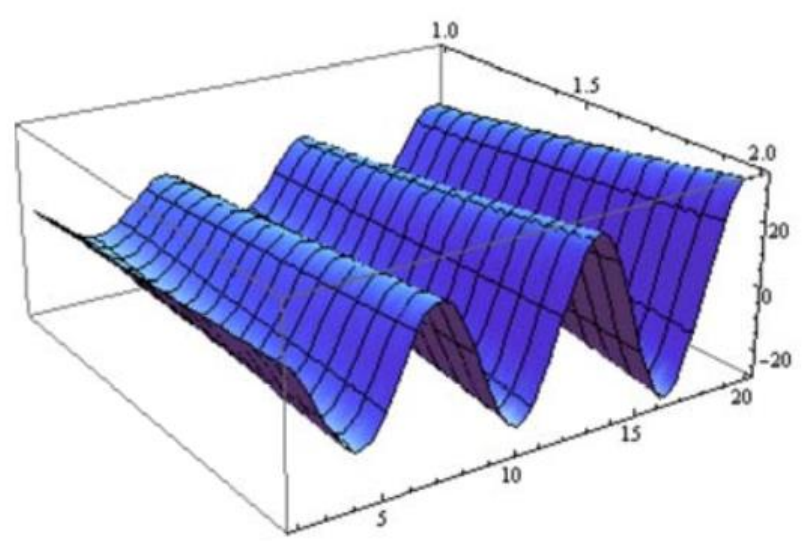

3. Kasus II memperoleh persamaan Telegraph

$$
v(x ; t)=\frac{1}{2}\left[f_{1}(x+c t)+f_{1}(x-c t)\right]+\frac{1}{2 c} \int_{x-c t}^{x+c t} f_{2}(\xi) d \xi
$$

Dan simulasinya dengan nilai tiap-tiap variabelnya:

$c=1$; interval $x=\{x \mid 1 \leq x \leq 2\} ; t=\{x \mid 2 \leq t \leq 20\}$ dan $f_{1}=x, f_{2}=x^{2}$

Untuk kasus II:

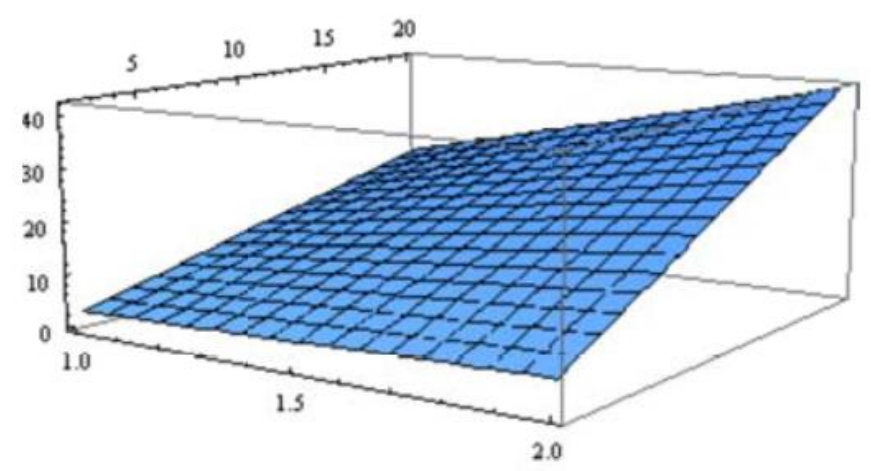




\section{Referensi}

[1] Pinsky, Mark A. 1998. Partial Differential Equations and Boundary-Value PRobles with Applications $3^{\text {rd }}$ edition. McGraw-Hill International Editions.

[2] Purcell, Edwin J. Varberg, Dale and Rigdon, Steve E.. 2001. Kalkulus. Jakarta: Erlangga.

[3] Anton, Howard. 1995, Aljabar Linear Elementer. Jakarta: Erlangga.

[4] Soedijono, Bambang, 2004. Kalkulus III, Jakarta: Universitas Terbuka.

[5] Bracewell, Ronald N.. 2000. The Fourier Transform and Its Applications. McGraw-Hill Higher Education.

[6] Suriasumantri, Jujun S.. 1987. Filsafat I/mu Sebuah Pengantar Populer. Jakarta: Pustaka Sinar Harapan.

[7] Tan, Soo T.. 2010. Calculus, Belmon USA: Brooks/Cole.

[8] Darmawijaya, Prof. Dr. Soeparna. 2006. Pengantar Analisis Real, Jurusan Matematika Fakultas MIPA UGM.

[9] Astuti, Fani Dwi, Fungsi Green dan Penerapannya pada Persamaan Diferensial Biasa. Skripsi Jurusan Matematika FMIPA Universitas Negeri Malang, lulus tahun 2007.

[10] Larson, Ron, Bruce H, Edwards. 2010. Calculus $9^{\text {th }}$ edition. USA: Brooks/Cole.

[11] Thomas, 2005, Calculus $11^{\text {th }}$ Including Second-Order Differential Equations, Addison-Weslay.

[12] Ayres, Frank, Jr., PhD, Elliott Mendelson, PhD. Schaum's Outline Series Calculus $5^{\text {th }}$ editions. USA: The McGraw-Hill Companies.

[13] Razali, Muhammad. 2008. Cara mudah menyelesaikan Matematika dengan Mathematica. Yogyakarta: Andi 